\title{
Gamma Knife Radiosurgery for Anterior Clinoid Process Meningiomas: A Series of 61 Consecutive Patients
}

\author{
Göktuğ Akyoldaş ${ }^{1}$, Ömer Batu Hergünsel' ${ }^{1}$, Meltem Yılmaz ${ }^{2}$, Meriç S Sengöz $^{3}$, Selçuk Peker ${ }^{7}$
}

\begin{abstract}
-OBJECTIVE: Gamma Knife radiosurgery (GKRS) outcomes for anterior clinoid process (ACP) meningiomas have not been specifically reported within any meningioma series. We present the initial and largest series in the literature that describes the presenting features, radiosurgery parameters, and radiologic and long-term clinical outcomes for 61 patients with ACP meningiomas treated with GKRS.
\end{abstract}

METHODS: Medical records were reviewed for 61 consecutive patients at a single center who underwent GKRS for ACP meningioma between 2008 and 2016.

RESULTS: Of 61 patients with ACP meningiomas, 49 $(80 \%)$ were treated with GKRS as primary treatment, and $12(20 \%)$ were treated with GKRS as an adjuvant therapy. Before GKRS, 29 patients presented with visual impairment and 50 patients presented with headache. Median patient age was 54.9 years. Median tumor volume was $3.2 \mathrm{~cm}^{3}$, and median margin dose was 12.0 Gy. The median radiologic follow-up time after GKRS was 75 months. During follow-up, tumor volume regressed in 37 cases $(61 \%)$ and remained unchanged in 24 cases $(39 \%)$. None of the patients experienced tumor volume progression. Tumor volume $<3 \mathrm{~cm}^{3}$ was an independent predictor of tumor volume regression after GKRS (univariate analysis, $\boldsymbol{P}=\mathbf{0 . 0 4 7}$; multivariate analysis, $P=0.049$ ). Of 29 patients who presented with visual impairment, 16 (55\%) improved after GKRS. None of the 61 patients developed new neurologic deficits after GKRS.

CONCLUSIONS: GKRS provides a high rate of tumor volume control for ACP meningiomas as well as a low complication rate. Excellent tumor volume control was associated with smaller tumor size only.

\section{INTRODUCTION}

$\Lambda$ nterior clinoid process (ACP) meningiomas arise from the superior, inferior, or medial meningeal covering of the ACP and account for $<9 \%$ of all meningiomas in the supratentorial region. ${ }^{\mathrm{I}}$ The intimate proximity of these tumors to crucial structures, in particular, the internal carotid artery and optic nerve, often prevents safe and complete surgical resection. Despite advances in microsurgical techniques and new surgical approaches and diagnostic modalities, ACP meningiomas continue to have very high complication and recurrence rates after surgical treatment. Among all intracranial meningiomas, those located on the ACP rank second only to clival meningiomas regarding these rates. $^{2,3}$ Gamma Knife radiosurgery (GKRS) has emerged as an important primary or adjuvant treatment modality for meningiomas. ${ }^{4-7}$ In the present study, we evaluated presenting features, radiosurgery parameters, and radiologic and clinical outcomes in a series of patients who underwent GKRS for ACP meningiomas.

\section{MATERIALS AND METHODS}

Patients

In this retrospective single-center study, we reviewed our center's database of patients with ACP meningioma who underwent GKRS between 2008 and 2016. Patients who had histologically diagnosed World Health Organization grade I ACP meningioma and patients who exhibited radiologic and clinical features consistent with benign ACP meningioma were considered for this series. The inclusion criteria were I) no history of malignancy and 2) a tumor

\section{Key words \\ - Anterior clinoid process \\ - Gamma Knife \\ - Meningioma \\ - Oncology \\ - Stereotactic radiosurgery}

\section{Abbreviations and Acronyms}

ACP: Anterior clinoid process

CN: Cranial nerve

GKRS: Gamma Knife radiosurgery

MRI: Magnetic resonance imaging
From the ${ }^{1}$ Department of Neurosurgery, Koç University School of Medicine, Istanbul:

${ }^{2}$ Medical Biotechnology; and ${ }^{3}$ Department of Radiation Oncology, School of Medicine, Acıbadem Mehmet Ali Aydınlar University, Istanbul, Turkey

To whom correspondence should be addressed: Göktuğ Akyoldaş, M.D.

[E-mail: goktug_akyoldas@hotmail.com]

Citation: World Neurosurg. (2020) 133:e529-e534.

https://doi.org/10.1016/j.wneu.2019.09.089

Journal homepage: www.journals.elsevier.com/world-neurosurgery

Available online: www.sciencedirect.com

1878-8750/\$ - see front matter ๔ 2019 Elsevier Inc. All rights reserved. 
located in the ACP that had magnetic resonance imaging (MRI) features consistent with meningioma (i.e., extra-axial location, uniform pattern of contrast enhancement, and dural attachment). ${ }^{8}$ The indications of primary GKRS treatment were I) tumor diameter $<3 \mathrm{~cm}$ and 2 ) cranial nerve $(\mathrm{CN})$ symptoms present for $<$ I2 months. The cases of 6 I consecutive patients whose records contained complete information after GKRS (i.e., a minimum of 2 years of clinical and imaging follow-up) were investigated.

\section{GKRS Methodology}

GKRS was performed using the Leksell Gamma Knife 4C model (between 2008 and 2012) and Leksell Gamma Knife Perfexion model (between 2012 and 2016) (Elekta AB, Stockholm, Sweden). All patients had a stereotactic frame placed under local scalp anesthetic. Stereotactic MRI was obtained, and the images were transferred to a computer using specific software for dose planning. In all cases, volumetric GKRS conformal target coverage was performed. The dose selection for each patient was adjusted based on 18 years of accumulated experience of our neurosurgical team with GKRS for meningioma and considering factors such as tumor volume and distance from critical structures (Figure 1).

Imaging Assessments and Clinical Follow-Up

After GKRS, each patient underwent serial contrast-enhanced MRI at 6-month intervals for the first year and yearly for 5 years thereafter. Clinical and radiologic assessments were done at each recheck examination. Radiologic follow-up ranged from 27 to 126 months (median, 75 months). Of the 6 I patients, 46 (75\%) had $>5$ years of clinical and radiological follow-up. Follow-up MRI was compared with MRI obtained before GKRS, and tumor volumes were calculated by measuring the maximal vertical, horizontal, and anteroposterior diameters of the tumor in all 3 imaging planes (i.e., axial, sagittal, and coronal). Tumor volume control was defined as tumor progression (increase $>25 \%$ of lesion size at diagnosis), stable (maximum $25 \%$ change in tumor volume), or regression (decrease $>25 \%$ ). ${ }^{8 \text {-Io }}$ In addition, all patients had a complete assessment by an ophthalmologist, including visual fields (Humphrey visual field testing). Visual field tests were compared with tests obtained before GKRS. Improvement in visual function was defined as $>30 \%$ reduction in visual field deficit.

\section{Statistical Analysis}

Univariate analysis was performed to estimate the prognostic significance of several variables associated with tumor regression and with improvement of visual impairment following GKRS. The $\chi^{2}$ test was used to compare categorical data. Student $t$ test was used to compare continuous data. Commercially available statistical processing software (IBM SPSS Version 24.0; IBM Corporation, Armonk, New York, USA) was used for all calculations, and P $<0.05$ was considered statistically significant.






\section{RESULTS}

\section{Patient Characteristics}

There were 52 women $(85 \%)$ and 9 men (15\%) with median age 54.9 years (range, $30-78$ years). Of 6 r patients, $49(80 \%)$ underwent GKRS as initial treatment for their tumor, and $12(20 \%)$ underwent GKRS as an adjuvant therapy for residual tumor or recurrence. None of the patients had received radiation therapy before GKRS. Patients' baseline characteristics are summarized in Table 1.

\section{Tumor Characteristics and Response}

The mean tumor volume was $4.3 \pm 3.6 \mathrm{~cm}^{3}$ (range, $0.2-15.5 \mathrm{~cm}^{3}$ ). There were $3 \mathrm{I}$ tumors located on the left ACP and 30 on the right ACP. As of the last MRI follow-up examination, no patient had experienced tumor volume progression after GKRS, 37 (6I\%) had experienced tumor regression, and $24(39 \%)$ had unchanged (stable) tumor volume. The actuarial tumor progression-free survival rate at maximum follow-up was $100 \%$.

Patients who had $<3 \mathrm{~cm}^{3}$ tumor volume at the time of GKRS were significantly more likely to experience tumor volume regression after GKRS (univariate analysis, $\mathrm{P}=0.047$; multivariate analysis, $\mathrm{P}=0.049$ ). Age, sex, history of prior surgery, and tumor margin dose were not associated with tumor regression after GKRS. Pre-GKRS factors associated with tumor volume regression after GKRS are listed in Table 2.

\section{Effect of Tumor Margin Dose}

The median tumor volume was $3.2 \mathrm{~cm}^{3}$ (mean, $4.3 \pm 3.6 \mathrm{~cm}^{3}$; range, $0.2-15.5 \mathrm{~cm}^{3}$ ). The median tumor margin dose was $\mathrm{I} 2 \mathrm{~Gy}$ (mean, II.8 Gy; range, Io-I4 Gy), and the median maximal dose was 24 Gy (mean, $24.3 \pm 2.4$ Gy; range, 20-30 Gy). The median isodose was 48.6 (range, $40 \%-60 \%$ ). Tumor margin dose was not correlated with tumor regression in our dose range (univariate analysis, $\mathrm{P}=0.083$; multivariate analysis, $\mathrm{P}=0.466$ ) or with improvement of visual impairment (univariate analysis, $\mathrm{P}=0.908$; multivariate analysis, $\mathrm{P}=0.957)$ after GKRS. The GKRS parameters evaluated are listed in Table 1.

\section{Clinical Response}

Apart from visual impairment, none of the 6r patients had neurologic deficits before GKRS. Of patients, $29(48 \%)$ had impaired visual function before they underwent GKRS. Ten of the 29 patients had a history of previous surgery for ACP meningioma. Visual impairment improved in $16(55 \%)$ of the 29 patients a mean 5 months (range, I.2- 56.4 months) after GKRS and remained unchanged in $\mathrm{I} 3(45 \%)$. Compared with patients who had not undergone previous surgery for ACP meningioma, the patients with this history were significantly more likely to have unchanged visual function after GKRS (univariate analysis, $\mathrm{P}=0.004$; multivariate analysis, $P=0.162$ ). Age, sex, tumor volume, and tumor margin dose were not correlated with improvement of visual impairment after GKRS. The pre-GKRS factors associated with improvement of visual impairment after GKRS are listed in Table 3.

At the time of writing, all 6r patients were alive, and no new visual function deficits or other neurologic deficits were observed after GKRS. The tumor control rate of the cohort was $100 \%$, and progression-free survival was $100 \%$ as of the last follow-up. Furthermore, there was no need for additional treatment after GKRS because none of the patients experienced tumor progression during follow-up.

\section{Adverse Effects of Radiation}

Three $(5 \%)$ of the 6I patients had cerebral edema before GKRS. In 2 cases, the edema had reduced by the 6-month follow-up examination; however, I patient showed progression of cerebral edema at 18 months. In this case, the edema resolved with steroid medication.

Table 1. Baseline Characteristics of 61 Patients with Anterior Clinoid Process Meningiomas Treated with Gamma Knife

Radiosurgery

Characteristic

Value

Age, years, median (range)

$54.9(30-78)$

Sex, male/female, number (\%)

$9(15) / 52(85)$

Tumor type and GKRS application, number (\%)

New tumor, primary $49(80)$

Residual tumor after surgical resection, adjuvant $12(20)$

Symptoms at initial presentation, number

Visual impairment 29

Headache $\quad 50$

Seizure

4

Visual impairment, number

Before SRS 29

After SRS

Tumor target volume, $\mathrm{cm}^{3}$, median (mean) (range) $3.2(4.3)(0.2-15.5)$

Patients grouped by tumor volume, number $(\%)$

$\begin{array}{ll}<3 \mathrm{~cm}^{3} & 30(49) \\ \geq 3 \mathrm{~cm}^{3} & 31 \text { (51) }\end{array}$

Tumor volume in patients grouped by surgical history, $\mathrm{cm}^{3}$, median (range)

New tumor, no prior surgery $\quad 4.14(0.2-15.5)$

Residual tumor

$5.05(1-15.4)$

Margin dose, Gy, median (range)

$11.8(10-14)$

Patients grouped by margin dose, number $(\%)$
$<12$ Gy
$20(32.8)$
$\geq 12 \mathrm{~Gy}$
$41(67.2)$

Isodose, median (range)

$48.6(40 \%-60 \%)$

Patients grouped by tumor location, number (\%)

\begin{tabular}{ll} 
Left ACP & $30(49.2)$ \\
\hline Right ACP & $31(50.8)$
\end{tabular}

GKRS, Gamma Knife radiosurgery; SRS, stereotactic radiosurgery; ACP, anterior clinoid process. 
Table 2. Pre-Gamma Knife Radiosurgery Variables Associated with Tumor Volume Regression After Treatment in Entire Series $(\mathrm{N}=61)$

\begin{tabular}{|lcc|}
\hline & \multicolumn{2}{c|}{$P$ Value } \\
\cline { 2 - 3 } Variable & Univariate & Multivariate \\
\hline Age, $\geq 55$ years versus $<55$ years & 0.353 & 0.565 \\
\hline Sex, male versus female & 0.381 & 0.848 \\
\hline Prior operation, yes versus no & 0.578 & 0.578 \\
\hline Tumor volume, $\geq 3 \mathrm{~cm}^{3}$ versus $<3 \mathrm{~cm}^{3}$ & $0.047^{*}$ & $0.049^{*}$ \\
\hline Tumor margin dose, $\geq 12$ Gy versus $<12 \mathrm{~Gy}$ & 0.083 & 0.466 \\
\hline *Statistically significant. & & \\
\hline
\end{tabular}

\section{DISCUSSION}

Despite advances in microsurgical techniques, ACP meningiomas remain challenging tumors to treat because of their close proximity to vital structures. Findings from our series of 6I consecutive cases demonstrated that GKRS provided excellent tumor volume control with a regression rate of $6 \mathrm{I} \%$ and promising improvement in patients with visual impairment as well as low rate of complication. Therefore, these findings suggest that GKRS can play a critical role as primary or adjuvant therapy for patients with ACP meningioma. Notably, no previous study has specifically examined clinical and radiologic outcomes for ACP meningiomas treated with GKRS.

Until recently, ACP meningiomas were frequently included in studies as sphenoidal meningiomas, and this partially masked


defined ACP meningiomas as a distinct group and divided them into 3 subgroups. Since this first classification system, several other classification schemes for ACP meningiomas have been developed in an attempt to predict surgical risk. ${ }^{\mathrm{II}-\mathrm{I} 5}$

The natural history of ACP meningiomas is not well described. It is possible to extract knowledge from the studies of various meningioma series. ${ }^{\mathrm{I}, 17}$ Oya et al. $^{\mathrm{I} 6}$ reported the natural history of

Table 3. Pre-Gamma Knife Radiosurgery Factors Potentially Correlated with Improvement of Visual Impairment After Treatment in Entire Series $(n=29)$

\begin{tabular}{|lcc|}
\hline & \multicolumn{2}{c|}{$P$ Value } \\
\cline { 2 - 3 } Variable & Univariate & Multivariate \\
\hline Age, $\geq 55$ years versus $<55$ years & 0.551 & 0.862 \\
\hline Sex, male versus female & 0.471 & 0.682 \\
\hline Prior operation, yes versus no & $0.004^{*}$ & 0.162 \\
\hline Tumor volume, $\geq 3 \mathrm{~cm}^{3}$ versus $<3 \mathrm{~cm}^{3}$ & 0.491 & 0.862 \\
\hline Tumor margin dose, $\geq 12$ Gy versus $<12 \mathrm{~Gy}$ & 0.908 & 0.957 \\
\hline *Statistically significant. & & \\
\hline
\end{tabular}

275 meningiomas, and they demonstrated growth in $44.0 \%$ by the linear diameter measurement and in $74.0 \%$ by the volumetric analysis with a mean follow-up of 4 years. Moreover, Bonnal et al. ${ }^{18}$ documented the natural history of 5 patients with ACP meningiomas who did not undergo surgical resection owing to advanced age. All 5 patients were alive at the time of writing (Io years after diagnosis in some cases), and all had unilateral visual loss and major oculomotor signs. Surgical resection has historically been the initial treatment modality for ACP meningioma. However, damage to the internal carotid artery, its branches, and/or CN II and CN III during surgical resection can have severe long-term effects for the patient. ${ }^{I}$ Because of these risks, documented rates of complete resection range from $59 \%$ to $83 \%{ }^{2,19,20}$ Moreover, neurologic deficits are important drawbacks, with reported rates of occurrence after surgical resection of $4 \%-29 \%$. ${ }^{2,19,20}$ Regarding tumor behavior after surgical resection of ACP meningioma, reports indicate recurrence-free rates of $93 \%, 80 \%$, and $68 \%$ at 5 , I0, and ${ }_{15}$ years after complete resection, with dramatically lower rates after subtotal resection $\left(63 \%, 45 \%\right.$, and $9 \%$, respectively). ${ }^{\mathrm{I}, 3,21}$

GKRS is a modern addition to the armamentarium of treatment modalities for ACP meningiomas. In recent decades, the pendulum has swung away from aggressive surgical resection and traditional fractioned radiation therapy for these tumors owing to promising outcomes after GKRS. The literature contains large series with favorable long-term results for intracranial meningiomas treated with GKRS. Recent reports on large series of these neoplasms at diverse locations have noted 5-year local control rates of $86.2 \%-98.5 \%$ and io-year rates of $73 \%-97 \%$. $^{4,22-3 \mathrm{I}}$ In our series of 6I ACP meningiomas treated with GKRS, the tumor control rate was $100 \%(6 \mathrm{I} \%$ of the patients exhibited regression, and $39 \%$ had unchanged tumor volume), and we observed 100\% progression-free survival at 2, 5, and 7 years. A retrospective assessment of 4565 patients with 5300 benign meningiomas having radiosurgery at I5 European Gamma Knife centers demonstrated good tumor volume control with a regression rate of $58 \%$, which is in line with the current study. ${ }^{7}$ Likewise, in their series of 4I6 patients with intracranial meningioma, Pollock et al. ${ }^{32}$ reported the tumor volume regression rate of $66.1 \%$ after radiosurgery treatment. Hung et al. ${ }^{33}$ presented the outcome of 95 cavernous sinus meningiomas. They reported a tumor regression rate of $74 \%$ at a median follow-up of 59 months. In the series by Harrison et al. ${ }^{34}$ of 252 patients with meningioma, the tumor volume regression rate was $67 \%$.

One main explanation for these findings may be that the tumor volumes of our patients at the time of diagnosis tended to be small (mean, $4.3 \mathrm{~cm}^{3}$ ). Many robust studies have identified larger tumor volume as the most important predictor of worse prognosis for benign meningiomas treated with GKRS..$^{35-38}$ Accordingly, we also did not observe tumor volume progression in our series.

Although the literature contains some differences regarding tumor margin dose in GKRS, the outcomes for meningiomas using margin doses of $\mathrm{I} 2-\mathrm{I} 8$ Gy were similar with respect to tumor volume control. ${ }^{39}$ It is not clear whether higher doses provide stability or regression. In our series of ACP meningiomas, the median tumor margin dose was I2 Gy, and we observed I00\% tumor control; however, we found no association between radiation dose (higher or lower) and tumor volume regression or 
stability (univariate analysis, $\mathrm{P}=0.083$; multivariate analysis, $\mathrm{P}=0.466)$.

Although improvement of neurologic deficits is not a primary goal of GKRS, several authors have reported that this therapy can improve neurologic symptoms in patients with meningioma. After GKRS treatment of cavernous sinus meningiomas, Pollock et al. ${ }^{40}$ and Park et al. ${ }^{8}$ reported improvement or resolution of $\mathrm{CN}$ deficits in $3 \mathrm{I} \%$ and $34 \%$ of their cases, respectively. In a recent study that evaluated $\mathrm{CN}$ outcomes after radiosurgery, Faramand et al. ${ }^{4 \mathrm{I}}$ found $46.5 \%$ of patients reported improvement. In addition, there are studies that presented higher rates of $\mathrm{CN}$ improvement. In one notable study conducted by Nicolato et $\mathrm{al}^{27}$ in 2002, symptom improvement was observed in $78.5 \%$ of patients with cavernous sinus meningioma who had GKRS as a primary treatment. We observed improvement of visual impairment after GKRS in $\mathrm{I} 6(55 \%)$ of 29 patients who presented with vision deficits. Patients with no history of previous surgery were more likely to show visual deficit improvement after GKRS (univariate analysis, $\mathrm{P}=0.004$; multivariate analysis, $P=0.162$ ). Of the 16 patients, Io showed tumor volume regression during follow-up. Moreover, in 6 of the 16 patients, tumor volume remained stable. The literature suggests that radiographic optic canal invasion is not necessary for visual compromise in ACP meningiomas. ${ }^{42}$ Therefore, it is quite difficult to establish a relationship between visual improvement and tumor volume before GKRS in the radiologic examinations. Moreover, the literature concluded that patients with a shorter duration of symptoms until GKRS were more likely to experience an improvement in $\mathrm{CN}$ impairment. ${ }^{4 \mathrm{I}}$ In addition, tumor volume regression is a significant factor for more favorable $\mathrm{CN}$ outcomes in patients with meningioma with $\mathrm{CN}$ impairment after GKRS. ${ }^{4 \mathrm{I}}$ Our patients showed a high rate of regression $(6 \mathrm{I} \%)$ after treatment and underwent GKRS $<\mathrm{I} 2$ months from onset of complaints. These published studies and our findings are able to explain the visual improvement rate of our patients.

Among large published meningioma series from centers that applied median doses of $\mathrm{I}_{2}-\mathrm{I}_{5} \mathrm{~Gy}$, rates of long-term complications (e.g., $\mathrm{CN}$ dysfunction, edema, and necrosis) have ranged $\mathrm{o} \%$ to $16 \% .^{4,16,17,19,21,25,43-45}$ A single-fraction dose of 10 Gy was associated with $<\mathrm{I} \%$ radiation-induced optic nerve neuropathy risk. ${ }^{46}$ In light of the literature, $\leq 8$ Gy doses was applied for preventing radiation-induced optic nerve neuropathy. In our series, I patient experienced worsening of prior edema after GKRS. Nevertheless, we observed no new neurologic deficits or worsening of neurologic function owing to the radiation.

Although our evaluation was retrospective and involved a limited sample size, it is the largest unique analysis of clinical features, radiologic features, and long-term outcomes for a series of patients with ACP meningioma. Other limitations are small mean tumor volume, and combining of results of the initial treatment group and residual tumor group. We could not perform volumetric analysis because almost every patient had follow-up MRI with different slice thickness at various centers. One of the key strengths of the present study was that each patient had a formal ophthalmologic examination for detailed visual assessment.

\section{CONCLUSIONS}

GKRS provides a significantly high rate of tumor volume control for ACP meningiomas. Neurologic function was unaffected by GKRS in all 6I of our cases, and a large proportion of patients with prior visual impairment experienced improvement in symptoms. Tumor volume regression was associated with smaller tumor size only. Improvement of visual impairment was independent from the predictive factors.

\section{REFERENCES}

I. Bassiouni H, Asgari S, Sandalcioglu IE, Seifert V, Stolke D, Marquardt G. Anterior clinoidal meningiomas: functional outcome after microsurgical resection in a consecutive series of 106 patients. Clinical article. J Neurosurg. 2009;III: I078-Iogo.

2. Al-Mefty O. Clinoidal meningiomas. J Neurosurg. I990;73:840-849.

3. Mathiesen T, Lindquist C, Kihlström L, Karlsson B. Recurrence of cranial base meningiomas. Neurosurgery. I996;39:2-9.

4. Lee JY, Niranjan A, McInerney J, Kondziolka D, Flickinger JC, Lunsford LD. Stereotactic radiosurgery providing long-term tumor control of cavernous sinus meningiomas. J Neurosurg. 2002; 97:65-72.

5. Pollock BE, Stafford SL. Results of stereotactic radiosurgery for patients with imaging defined cavernous sinus meningiomas. Int J Radiat Oncol Biol Phys. 2005;62:I427-I43I.

6. Talacchi A, Hasanbelliu A, D'Amico A, et al. Long-term follow-up after surgical removal of meningioma of the inner third of the sphenoidal wing: outcome determinants and different strategies [e-pub ahead of print]. Neurosurg Rev(2018). https://doi.org/I0.I007/sIoI43-0I8IOI8-I, accessed June I, 2019.

7. Santacroce A, Walier M, Régis J, et al. Long-term tumor control of benign intracranial meningiomas after radiosurgery in a series of 4565 patients. Neurosurgery. 2012;70:32-39 [discussion: 39].

8. Park KJ, Kano H, Iyer A, et al. Gamma Knife stereotactic radiosurgery for cavernous sinus meningioma: long-term follow-up in 200 patients. J Neurosurg. 20I8;I:I-IO.

9. Seo Y, Kim DG, Kim JW, Han JH, Chung HT, Paek SH. Long-term outcomes after Gamma Knife radiosurgery for benign meningioma: a single institution's experience with 424 patients. Neurosurgery. 2018;83:1040-1049.

Io. Feigl GC, Samii M, Horstmann GA. Volumetric follow-up of meningiomas: a quantitative method to evaluate treatment outcome of Gamma Knife radiosurgery. Neurosurgery. 2007;6I:28I-286 [discussion: 286-287].
II. Pamir MN, Belirgen M, Ozduman K, Kilic T, Ozek M. Anterior clinoidal meningiomas: analysis of 43 consecutive surgically treated cases. Acta Neurochir (Wien). 2008;150:625-635.

I2. Goel A, Gupta S, Desai K. New grading system to predict resectability of anterior clinoid meningiomas. Neurol Med Chir (Tokyo). 2000;40:610-6I6.

I3. Lee JH, Jeun SS, Evans J, Kosmorsky G. Surgical management of clinoidal meningiomas. Neurosurgery. 200I;48:IOI2-IOI9.

I4. Puzzilli F, Ruggeri A, Mastronardi L, Agrillo A, Ferrante L. Anterior clinoidal meningiomas: report of a series of 33 patients operated on through the pterional approach. Neuro Oncol. I999; I:I88-I95.

I5. Risi P, Uske A, de Tribolet N. Meningiomas involving the anterior clinoid process. Br J Neurosurg. 1994;8:295-305.

I6. Oya S, Kim SH, Sade B, Lee JH. The natural history of intracranial meningiomas. J Neurosurg. 2OII;II4:I250-I256.

I7. Sughrue ME, Kane AJ, Shangari G, et al. The relevance of Simpson grade I and II resection in 
modern neurosurgical treatment of World Health Organization grade I meningiomas. J Neurosurg. 20IO;II3:IO29-IO35.

I8. Bonnal J, Thibaut A, Brotchi J, Born J. Invading meningiomas of the sphenoid ridge. J Neurosurg. I980;53:587-599.

I9. Al-Mefty O. Clinoidal meningiomas. In: Meningiomas. New York, NY: Raven Press; I991:427-443.

20. Samii M, Ammirati M. Medial sphenoidal wing meningiomas. In: Samii M, ed. Surgery of Skull Base Meningiomas. Berlin: Springer; I993:35-4I.

2I. Mirimanoff RO, Dosoretz DE, Linggood RM, Ojemann RG, Martuza RL. Meningioma: analysis of recurrence and progression following neurosurgical resection. J Neurosurg. I985;62:18-24.

22. DiBiase SJ, Kwok Y, Yovino S, et al. Factors predicting local tumor control after Gamma Knife stereotactic radiosurgery for benign intracranial meningiomas. Int J Radiat Oncol Biol Phys. 2004;60: I5I5-I5I9.

23. Hasegawa T, Kida Y, Yoshimoto M, Koike J, Iizuka H, Ishii D. Long-term outcomes of Gamma Knife surgery for cavernous sinus meningioma. J Neurosurg. 2007;107:745-75I.

24. Iwai Y, Yamanaka K, Ikeda H. Gamma Knife radiosurgery for skull base meningioma: longterm results of low-dose treatment. Clinical article. J Neurosurg. 2008;109:804-810.

25. Kollová A, Liscák R, Novotný J Jr, Vladyka V, Simonová G, Janousková L. Gamma Knife surgery for benign meningioma. J Neurosurg. 2007;107: 325-336.

26. Kreil W, Luggin J, Fuchs I, Weigl V, Eustacchio S, Papaefthymiou G. Long term experience of Gamma Knife radiosurgery for benign skull base meningiomas. J Neurol Neurosurg Psychiatry. 2005; 76:I425-I430.

27. Nicolato A, Foroni R, Alessandrini F, Maluta S, Bricolo A, Gerosa M. The role of Gamma Knife radiosurgery in the management of cavernous sinus meningiomas. Int J Radiat Oncol Biol Phys. 2002; 53:992-1000.

28. Sheehan JP, Starke RM, Kano H, et al. Gamma Knife radiosurgery for sellar and parasellar meningiomas: a multicenter study. J Neurosurg. 20I4; I2O:I268-I277.
29. Stafford SL, Pollock BE, Foote RL, et al. Meningioma radiosurgery: tumor control, outcomes, and complications among I9o consecutive patients. Neurosurgery. 2001;49:1029-1038.

3o. Starke RM, Williams BJ, Hiles C, Nguyen JH, Elsharkawy MY, Sheehan JP. Gamma Knife surgery for skull base meningiomas. Clinical article. J Neurosurg. 2012;116:588-597.

3I. Takanashi M, Fukuoka S, Hojyo A, Sasaki T, Nakagawara J, Nakamura H. Gamma Knife radiosurgery for skull-base meningiomas. Prog Neurol Surg. 2009;22:96-III.

32. Pollock BE, Stafford SL, Link MJ, Brown PD, Garces YI, Foote RL. Single-fraction radiosurgery of benign intracranial meningiomas. Neurosurgery. 2012;71:604-612 [discussion: 613].

33. Hung YC, Lee CC, Guo WY, et al. Gamma Knif radiosurgery for the treatment of cavernous sinus meningiomas: post-treatment long-term clinica outcomes, complications, and volume changes. J Neurooncol. 2019;I43:26I-270.

34. Harrison G, Kano H, Lunsford LD, Flickinger JC, Kondziolka D. Quantitative tumor volumetric responses after Gamma Knife radiosurgery for meningiomas. J Neurosurg. 2016;124:I46-I54.

35. Bledsoe JM, Link MJ, Stafford SL, Park PJ, Pollock BE. Radiosurgery for large-volume ( $>$ io $\mathrm{cm}_{3}$ ) benign meningiomas. J Neurosurg. 2010;II2: 951-956.

36. Flannery TJ, Kano H, Lunsford LD, et al. Longterm control of petroclival meningiomas through radiosurgery. J Neurosurg. 2010;112:957-964.

37. Ganz JC, Reda WA, Abdelkarim K. Gamma Knife surgery of large meningiomas: early response to treatment. Acta Neurochir (Wien). 2009;I5I:I-8.

38. Haselsberger K, Maier T, Dominikus $\mathrm{K}$, et al. Staged Gamma Knife radiosurgery for large critically located benign meningiomas: evaluation of a series comprising 20 patients. J Neurol Neurosurg Psychiatry. 2009;80:II72-II75.

39. Kondziolka D, Patel AD, Kano H, Flickinger JC, Lunsford LD. Long-term outcomes after Gamma Knife radiosurgery for meningiomas. Am J Clin Oncol. 2016;39:453-457.

40. Pollock BE, Stafford SL, Link MJ, Garces YI, Foote RL. Single-fraction radiosurgery of benign cavernous sinus meningiomas. J Neurosurg. 2013; IIg:675-682.

4I. Faramand A, Kano H, Niranjan A, et al. Crania nerve outcomes after primary stereotactic radiosurgery for symptomatic skull base meningiomas. J Neurooncol. 2018;139:34I-348.

42. Sughrue M, Kane A, Rutkowski MJ, Berger MS McDermott MW. Meningiomas of the anterior clinoid process: is it wise to drill out the optic canal? Cureus. 2015;7:e32I.

43. Eustacchio S, Trummer M, Fuchs I, Schröttner O, Sutter B, Pendl G. Preservation of cranial nerve function following Gamma Knife radiosurgery for benign skull base meningiomas: experience in I2 patients with follow-up of 5 to 9.8 years. Acto Neurochir Suppl. 2002;84:71-76.

44. Feigl GC, Samii M, Horstmann GA. Volumetric follow-up of meningiomas: a quantitative method to evaluate treatment outcome of Gamma Knife radiosurgery. Neurosurgery. 2007;6I:28I-287.

45. Hudgins WR, Barker JL, Schwartz DE, Nichols TD. Gamma Knife treatment of Ioo consecutive meningiomas. Stereotact Funct Neurosurg. I996;66(suppl I):I2I-I28.

46. Milano MT, Grimm J, Soltys SG, et al. Single- and multi-fraction stereotactic radiosurgery dose tolerances of the optic pathways [e-pub ahead of print]. Int J Radiat Oncol Biol Phys https://doi.org/Io Ior6/j.ijrobp.2018.oI.053. Accessed June I, 2019.

Conflict of interest statement: The authors declare that the article content was composed in the absence of any commercial or financial relationships that could be construed as a potential conflict of interest.

Received 26 June 2019; accepted 16 September 2019

Citation: World Neurosurg. (2020) 133:e529-e534.

https://doi.org/10.1016/j.wneu.2019.09.089

Journal homepage: www.journals.elsevier.com/worldneurosurgery

Available online: www.sciencedirect.com

1878-8750/\$ - see front matter (C) 2019 Elsevier Inc. All rights reserved. 